\title{
Pelvic floor muscles after birth: Do unstable shoes have an effect on pelvic floor activity and can this be measured reliably? - A feasibility study Der Beckenboden nach der Geburt: Verändern instabile Schuhe die Aktivität und kann diese reliabel gemessen werden? - Eine Machbarkeitsstudie
}

\author{
Eveline Graf ${ }^{1 *}$, Barbara Borner ${ }^{2}$, Jessica Pehlke ${ }^{2}$ \\ ${ }^{1}$ Zürcher Hochschule für Angewandte Wissenschaften, \\ Institut für Physiotherapie, 8401 Winterthur, Schweiz \\ *eveline.graf@zhaw.ch \\ ${ }^{2} Z$ Zurcher Hochschule für Angewandte Wissenschaften, \\ Institut für Hebammen, 8401 Winterthur, Schweiz
}

Received 5 December 2018, accepted 13 September 2019

\begin{abstract}
Background: Women often suffer from urinary incontinence after childbirth. Pelvic floor muscle training is an evidenced-based intervention to prevent urinary incontinence and improve its symptoms. Aim: The primary purpose of this study was to determine if there is a change in the activation of the pelvic floor muscles with different extrinsic parameters (barefoot versus unstable shoe). Second, we wanted to define variables that can be measured reliably and correlated with pelvic floor activity. Methods: Data of 15 women who were 8 weeks to 6 months postpartum were analyzed. Two conditions ("barefoot" and "kyBoot") were tested, with each participant performing three different tasks: walking, standing with an active pelvic floor, and standing with a passive pelvic floor. Three-dimensional kinematics of the body were recorded. Activity of the abdominal, back, and gluteal muscles was measured using surface electromyography (EMG). The activity of the pelvic floor was recorded using a vaginal electrode. Maximum pelvic floor activity was compared for each condition, and correlations among pelvic floor activity, kinematic variables, and skeletal muscle activity were determined. Results: The maximum activity of the pelvic floor while walking was significantly higher when participants were barefoot than when they were wearing kyBoot shoes. For the standing trials, no significant differences between the conditions were detected. No surrogate marker was found to measure the pelvic floor activity. Conclusion: With regard to the pelvic floor musculature, no recommendation is possible in favor of or against wearing unstable shoes. Technical developments are necessary to provide solutions to reliably measure the pelvic floor activity.
\end{abstract}

\begin{abstract}
Hintergrund: Nach einer Geburt leiden Frauen oftmals an Harninkontinenz. Training der Beckenbodenmuskulatur hat nachweislich einen präventiven wie auch mildernden Effekt auf Harninkontinenz.

Ziel: Das primäre Ziel dieser Machbarkeitsstudie war es, den Effekt von Schuhwerk (kyBoot und barfuß) auf die Aktivität der Beckenbodenmuskulatur zu untersuchen. Das sekundäre Ziel war es, Variablen zu definieren, welche in Laborumgebung reliabel messbar sind und Aufschluss auf die Beckenbodenaktivität geben.

Methodik: 15 Frauen, 8 Wochen bis 6 Monate nach Geburt, wurden für diese Studie rekrutiert. Zwei Schuhkonditionen (barfuß und kyBoot) und 3 Bewegungsaufgaben (Gehen, Stehen mit aktivem und passivem Beckenboden) wurden analysiert. Die Aktivität des Beckenbodens wurde mittels einer vaginalen Elektrode erfasst. Dreidimensionale Kinematik wurde erfasst. Die Aktivität von abdominaler, Rücken- und glutealer Muskulatur wurde mittels Oberflächen-Elektromyographie erhoben. Die maximale Beckenbodenaktivität mit den zwei Schuhkonditionen wurde verglichen und die Korrelation der Beckenbodenaktivität mit kinematischen Variablen und Oberflächenmuskulatur berechnet.

Resultate: Die maximale Aktivität des Beckenbodens während des Gehens war signifikant höher barfuß. Für die Steh-Versuche wurden keine Unterschiede zwischen den Schuhkonditionen gefunden. Es wurden keine Variablen gefunden, welche mit der Aktivität der Beckenbodenmuskulatur korrelierten.

Schlussfolgerung: Bezüglich Aktivierung der Beckenbodenmuskulatur kann keine Empfehlung für oder gegen das Tragen von kyBoot abgegeben werden. Es sind technische Entwicklungen notwendig, um die Beckenbodenmuskulatur reliabel erfassen zu können.
\end{abstract}

\section{Keywords}

unstable shoe - barefoot - pelvic floor musculature - postpartum - vaginal electromyography - feasibility study

\section{Keywords}

instabiler Schuh - barfuß - Beckenbodenmuskulatur - postpartal - vaginale Elektromyographie - Machbarkeitsstudie 


\section{INTRODUCTION}

Pregnancy and childbirth are risk factors for the development of urinary incontinence (Danforth et al., 2006; Fritel, Ringa, Quiboeuf, \& Fauconnier, 2012; Menezes, Pereira, \& Hextall, 2010; Milsom et al., 2009; Sangsawang \& Sangsawang, 2013; Zhou et al., 2018). During a women's first 3 months postpartum, the overall prevalence of urinary incontinence is $33 \%$, with $12 \%$ of all women suffering from weekly and $3 \%$ from daily incontinence (Thom \& Rortveit, 2010; Wesnes, Hunskaar, \& Rortveit, 2012). Urinary incontinence often continues for several years after pregnancy (Gyhagen, Bullarbo, Nielsen, \& Milsom, 2013; Hansen, Svare, Viktrup, Jørgensen, \& Lose, 2012; MacArthur et al., 2006). In middle-aged or older women, the prevalence of urinary incontinence is between $30 \%$ and $60 \%$ and increases with age (Milsom et al., 2009). The large variation in the prevalence of urinary incontinence may be due to different study designs, different methods used to assess urinary incontinence, different definitions of urinary incontinence, and a selection bias (Milsom et al., 2009; Pregazzi et al., 2002; Thom \& Rortveit, 2010; Wesnes et al., 2012).

The exact etiology and pathophysiology of urinary incontinence after pregnancy and birth are still unknown (Fritel et al., 2012; Fuselier, Hanberry, Lovin, \& Gomelsky, 2018; Živković et al., 2016). A potential cause seems to be a weakness of the pelvic supportive structures (Hilde, Stær-Jensen, Ellström Engh, Brækken, \& Bø, 2012; Mørkved, Salvesen, B $\varnothing$, \& Eik-Nes, 2004; Sangsawang, 2014; Sangsawang \& Sangsawang, 2013; Van Geelen, Ostergard, \& Sand, 2018). During pregnancy, hormonal changes as well as changes in collagen structure occur, making the pelvic floor more elastic and preparing it for birth. These changes can lead to weakening of the pelvic floor musculature (Bartling \& Zito, 2016; Sangsawang \& Sangsawang, 2013). The growing uterus and the weight gained by the fetus and the childbearing woman lead to an increased intra-abdominal pressure, which may also play a role in developing urinary incontinence (Allahdin \& Kambhampati, 2012; Bartling \& Zito, 2016; Fuselier et al., 2018; Sangsawang, 2014).

Pelvic floor muscle training before and after birth is an evidenced-based intervention to prevent urinary incontinence and its symptoms (Dumoulin, Cacciari, \& Hay-Smith, 2018; Dumoulin, Glazener, \& Jenkinson, 2011; Mørkved \& Bø, 2014; Price, Dawood, \& Jackson, 2010; Wesnes \& Lose, 2013). In fact, for women with urinary incontinence, pelvic floor muscle training should be a first-line therapy $(\mathrm{B} \varnothing, 2012)$. It is simple to perform and available to all women (Allahdin \& Kambhampati, 2012).
While most women are aware of the effectiveness of pelvic floor muscle training (Hermansen, O'Connell, \& Gaskin, 2010), prevention methods are not used enough (Hermansen et al., 2010). Few women perform regular pelvic floor muscle training antenatally and postpartum (Allahdin \& Kambhampati, 2012; Bø, Haakstad, \& Voldner, 2007). After childbirth, women are busy caring for their newborns. They often suffer from insomnia and exhaustion (Corwin \& Arbour, 2007). Unless urinary incontinence causes distress, training of the pelvic floor musculature is not a priority, especially in households with small children.

However, urinary incontinence during pregnancy and after delivery usually has just a mild to moderate effect on the quality of life (Abdullah et al., 2016; Arrue et al., 2010; Dolan et al., 2004; Hansen et al., 2012; Kocaöz, Talas, \& Atabekoğlu, 2010; Martínez Franco, Parés, Lorente Colomé, Méndez Paredes, \& Amat Tardiu, 2014). According to Kocaöz et al. (2010), one reason for this might be that women perceive urinary incontinence during pregnancy and birth as temporary. In addition, urinary incontinence is still a big taboo (Elenskaia et al., 2011; Marecki \& Seo, 2010).

In order to achieve high adherence to a training regimen, it needs to be easy for the target group of young mothers to integrate pelvic floor muscle training into a daily routine. Little is known to date about extrinsic factors that may activate the pelvic floor muscles. There is no research on measuring the effect of gait on the pelvic floor, although it has been shown that reduced foot flexibility may lead to increased impact forces, which may, in turn, be related to urinary incontinence (I. E. Nygaard, Glowacki, \& Saltzman, 1996). Changes to the foot are also known to alter the kinematics of the hip, pelvis, and thorax (Khamis \& Yizhar, 2007; Lee, 2018; Tateuchi, Wada, \& Ichihashi, 2011). In light of this, footwear designed to change the kinematics of walking and standing may influence the pelvic region.

Studies performed on the Masai Barefoot Technology (MBT) shoe have shown that wearing unstable footwear can lead to altered muscle activation and sway while standing (Landry, Nigg, \& Tecante, 2010; Nigg, Hintzen, \& Ferber, 2006) as well as walking (Nigg et al., 2006; Stöggl, Haudum, Birklbauer, Murrer, \& Müller, 2010). The kyBoot produced by kybun AG (Roggwil, Switzerland) is another example of an unstable shoe, it has a soft-elastic outsole and an air buffer in the center. It is assumed that the findings for the MBT shoe also apply to the kyBoot shoe. In both cases, more stabilization is needed while walking and standing than while barefoot. Wearing kyBoot shoes could, therefore, exercise the pelvic floor musculature.

The activity of the pelvic floor muscles in dynamic situations can be measured noninvasively with vaginal 
electromyography (EMG; Luginbuehl et al., 2013). This has a limited reliability (Luginbuehl et al., 2013) and is, therefore, unfit for repeated measurements. For a possible longitudinal study examining the effect of unstable shoes on the pelvic floor muscles, it would be necessary to have a more reliable method. There may be other more reliable variables providing information on pelvic floor activity that can be quantified in a movement laboratory, such as kinematic variables or skeletal muscle activation.

Previous research has provided evidence of co-activation of the pelvic floor muscles and abdominal muscles (Junginger, Baessler, Sapsford, \& Hodges, 2010; Neumann \& Gill, 2002; Sapsford \& Hodges, 2001; Sapsford et al., 2001). Those studies used fine-wire EMG to record intramuscular activity. This approach is invasive and its application in a study design involving walking is limited. Finding a surrogate marker that can be recorded noninvasively would allow for a longitudinal study measuring the effectiveness of an intervention such as unstable shoes on the pelvic floor.

\section{AIM OF THE STUDY}

The primary purpose of this feasibility study was to determine if there is a change in the activation of the pelvic floor muscles in postpartum women with different extrinsic parameters (barefoot versus kyBoot shoes). Second, we wanted to define variables that can be measured with high reliability in the laboratory and can be correlated with the activity of the pelvic floor muscle activity.

\section{METHODS}

\section{Design}

The study was designed as a cross-sectional, withinsubject comparison, feasibility study.

\section{Sample}

A total of 20 women who were 8 weeks to 6 months postpartum with no previous experience with unstable footwear were recruited for the study, and the data of 15 women were analyzed (mean \pm std age: $32 \pm 2.7$ years; height: $1.7 \pm 0.7 \mathrm{~m}$; mass: $63.2 \pm 8.2 \mathrm{~kg}$ ). The main exclusion criteria were severe incontinence (according to ICIQ-UI short form), urinary tract infections, chronic diseases, or injuries affecting the participant's gait pattern. Five data sets had to be excluded because of missing data or premature termination of the data collection. Participants were all free of diseases or injuries and had, if any, only mild stress incontinence. All women signed informed written consent approved by the local ethics committee (ID: KEK-ZH-Nr. 2015-0126).

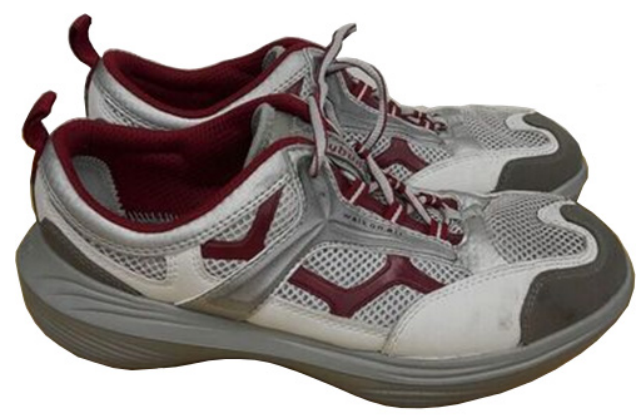

Figure 1: kyBoot used for data collection

\section{Data collection process}

Two footwear conditions ("barefoot" and "kyBoot", Figure 1) were tested in random order by each participant. The participants performed three tasks: walking at selfselected speed (walk), standing for $15 \mathrm{~s}$ with an active pelvic floor (stance active), and standing for $15 \mathrm{~s}$ without pelvic floor activation (stance passive). The participants were instructed to stand upright during stance passive and to contract their pelvic floor as much as possible during stance active.

Three-dimensional kinematics of the body were recorded using a marker-based 12-camera system $(200 \mathrm{~Hz}$, Vicon Motion Systems, Oxford, UK). Markers were placed on the body according to the Plug-In Gait (PiG) full body marker set (Davis, Õunpuu, Tyburski, \& Gage, 1991). The joint angles in the sagittal plane of the ankle, knee, and hip, as well as the global orientation in the sagittal plane of the pelvis were calculated. The activity of the following muscles (left and right) was recorded using surface EMG (1000 Hz, myon AG, Schwarzenberg, Switzerland): M. Obliquus Externus (ObliExt), M. Rectus Abdominis (RectAbd), M. Erector Spinae (ErecSpi), M. Multifidii Lumbalis (MultLum), and M. Gluteus Maximus (GlutMax). Electrodes (Ambu BlueSensor, Ambu, Ballerup, Denmark) were placed on the prepared skin (shaven and cleaned) according to the SENIAM guidelines (Hermens et al., 1999) and recorded by the Vicon system synchronized with the marker data. The activity of the pelvic floor was recorded using a vaginal electrode (MultiBioSensors) and NeXus-10 (Mind Media BV, Herten, The Netherlands) at 2,048 Hz.

The participants were instructed on how to insert the electrode and inserted the lubricated electrode themselves. To synchronize the pelvic floor EMG signal with the remaining data, an external trigger was added to the NeXus-10 device, which sent a trigger signal to the Vicon system as well as the NeXus-10. Before the tasks were performed, participants were instructed to perform a maximum voluntary contraction (MVC) task by contracting their pelvic floor as hard as possible three times in a row at their own rate of contraction. The 
measurement was used to normalize the signal of the pelvic floor activity signal during the subsequent tasks.

\section{Data analysis}

All kinematic data were filtered using a mean-squarederror Woltring filter with a smoothing level of $10 \mathrm{~mm}^{2}$, and joint angles were calculated following the $\mathrm{PiG}$ procedure in Vicon Nexus 2.7. The surface EMG signals of the skeletal muscles were filtered (second-order Butterworth bandpass filter 10-450 Hz), rectified, and a root-mean-square (RMS) envelope was calculated. The EMG of the pelvic floor was filtered (second-order Butterworth bandpass filter 10-1000 Hz), rectified, and an RMS envelope calculated. Subsequently, all data were synchronized, with gait data being expressed from $0 \%$ to $100 \%$ of a gait cycle. All data processing and analysis were performed in MATLAB (The MathWorks, Natick, USA).

\section{Variables}

To address the first aim of the study, the maximum activity of the pelvic floor during the stance (active and passive) and walking trials was compared between barefoot and kyBoot using a paired t-test with a significance level of 0.05 . Also, the pelvic floor muscle activity was compared between footwear conditions during $0.5 \mathrm{~s}$ in the middle of the standing trials.

To answer the secondary aim, the joint angles (ankle-, knee-, and hip-joint angles in the sagittal plane) and skeletal muscle activity were correlated with the activity of the pelvic floor at the moment of maximal pelvic floor activity for all tasks using the Pearson correlation coefficient.

\section{RESULTS}

Pelvic floor activity while walking in kyBoot shoes or barefoot showed two peaks, at around $20 \%$ and $70 \%$ of the gait cycle $(0 \%$ of gait cycle represent initial foot-ground contact, $100 \%$ of gait cycle represents consecutive footground contact of the same foot; Figure 2). The maximum activity was significantly higher (p-value: 0.02 ) for the barefoot than for the kyBoot condition (112\% vs. $90 \%$ of MVC; see Table 1). For the standing trials (stance active and passive), no significant differences between the conditions were observed for maximal and mid activities of the pelvic floor (Table 1).

The Pearson correlation coefficient between maximum pelvic floor activity and a variety of variables (measured at the same time point) was calculated to determine if the activity of the pelvic floor could be determined by a surrogate variable. The data were analyzed separately for

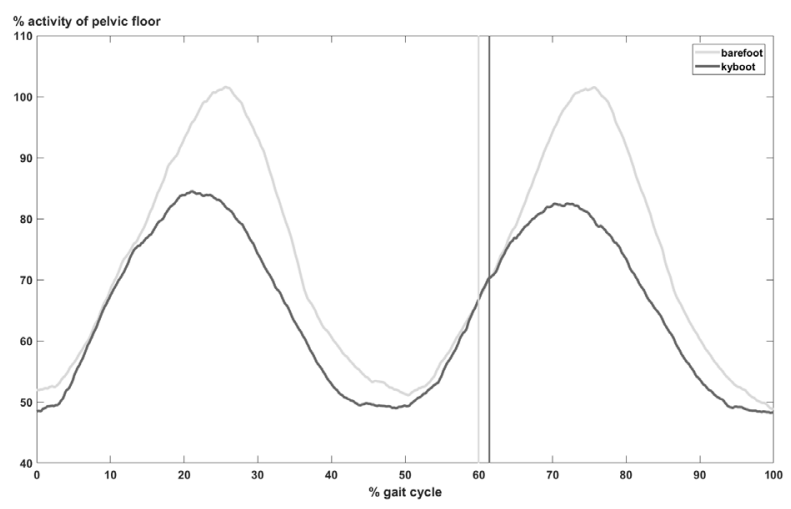

Figure 2: Pelvic floor activity (in \% of MVC) over the gait cycle for barefoot (light grey) and kyBoot (dark grey). The vertical lines represent foot-off.

Table 1: Mean maximum and mid pelvic floor activity for "kyBoot" and "barefoot" for all tasks. The last column lists p-values of comparison. Bold indicates a significant difference between "kyBoot" and "barefoot" based on a significance level of $p<0.05$

\begin{tabular}{c|c|c|c|c}
\hline \multirow{2}{*}{} & & \multicolumn{2}{|c}{$\begin{array}{c}\text { Mean pelvic floor } \\
\text { activity (in \% MVC) }\end{array}$} & p-Value \\
\hline \multirow{2}{*}{ Walking } & Maximal activity & $\mathbf{9 0 . 0}$ & $\mathbf{1 1 2 . 2}$ & $\mathbf{0 . 0 2}$ \\
\hline \multirow{2}{*}{$\begin{array}{c}\text { Stance } \\
\text { active }\end{array}$} & Maximal activity & 76.0 & 64.3 & 0.59 \\
\cline { 2 - 5 } & Mid activity & 57.2 & 52.6 & 0.84 \\
\hline \multirow{2}{*}{$\begin{array}{c}\text { Stance } \\
\text { passive }\end{array}$} & Maximal activity & 16.0 & 17.7 & 0.72 \\
\cline { 2 - 5 } & Mid activity & 14.3 & 15.6 & 0.79 \\
\hline
\end{tabular}

the two conditions "kyBoot" and "barefoot" (Table 2). The highest correlation coefficient for joint angles was observed for the knee angle during stance active with kyBoot (0.48). However, the same variable for other conditions or tasks was much smaller. For the muscles, all correlation coefficients were $\leq 0.26$ (Table 2 ).

\section{DISCUSSION}

The primary aim of this study was to determine if unstable footwear was able to alter the activation of the pelvic floor muscles in postpartum women. The second aim was to identify the variables that can be reliably measured in a movement laboratory, which provide information on the activation of the pelvic floor muscles.

The pelvic floor activity during walking yielded significantly more activation while barefoot compared with "kyBoot." No difference in activation was observed for the standing tasks. Therefore, the initial hypothesis that the pelvic floor may need to be activated more while wearing an unstable shoe had to be rejected. The kyBoot has a soft-elastic outsole with an air cushion in the center. This could result in more cushioning for the foot 
Table 2: Pearson correlation coefficient between pelvic floor activity and kinematic/skeletal muscles variables for "kyBoot" and "barefoot."

\begin{tabular}{|c|c|c|c|c|c|c|}
\hline \multirow{3}{*}{$\begin{array}{l}\text { Pelvic floor activity } \\
\text { versus }\end{array}$} & \multicolumn{6}{|c|}{ Pearson correlation coefficient } \\
\hline & \multicolumn{2}{|c|}{ Walking } & \multicolumn{2}{|c|}{ Stance active } & \multicolumn{2}{|c|}{ Stance passive } \\
\hline & kyBoot & Barefoot & kyBoot & Barefoot & kyBoot & Barefoot \\
\hline Ankle angle & -0.06 & 0.03 & 0.25 & 0.14 & 0.09 & 0.10 \\
\hline Knee angle & 0.15 & 0.18 & 0.48 & -0.10 & 0.15 & 0.33 \\
\hline Hip angle & 0.04 & 0.10 & 0.39 & 0.02 & 0.27 & 0.38 \\
\hline Pelvis angle & 0.10 & 0.23 & 0.28 & 0.18 & 0.29 & 0.29 \\
\hline ObliExt & 0.02 & -0.09 & 0.25 & -0.18 & 0.14 & -0.01 \\
\hline RectAbd & 0.00 & -0.03 & 0.09 & -0.35 & -0.10 & -0.17 \\
\hline ErecSpi & -0.11 & -0.09 & -0.12 & -0.40 & -0.08 & 0.06 \\
\hline MultLum & -0.07 & -0.09 & -0.04 & -0.41 & -0.26 & -0.10 \\
\hline GlutMax & 0.26 & 0.23 & 0.17 & -0.35 & -0.27 & -0.27 \\
\hline
\end{tabular}

during landing than while barefoot. A more cushioned landing of the foot may actually require less activity in the pelvic floor despite the instability caused by the shoe. However, there is a lack of knowledge about the effect that walking has on the pelvic floor muscles, which is why it was impossible to consult other studies about this phenomenon.

This study compared the pelvic floor activation while wearing kyBoot shoes with that while barefoot. This approach was chosen because it was felt that bare feet may best represent the situation of women at home after childbirth. It is unknown how the activity of the pelvic floor is affected by the wearing of standard outdoor footwear. It is possible that wearing kyBoot shoes would result in an increase of pelvic floor activity compared with regular footwear. However, such a hypothesis needs to be examined in future studies.

This study measured the short-term effect of unstable footwear on the activity of the pelvic floor muscles while walking and standing. Ultimately, it would be of interest to know if unstable shoes are able to introduce a training effect on the pelvic floor muscles for a prolonged period of time. Future research is needed to investigate this.

A serious limitation is the limited reliability of vaginal EMG (Luginbuehl et al., 2013). The placement of the electrode only has limited reliability. The participants were asked to place the prominent bulge of the electrode ventrally. However, there is no suitable way to standardize the placement according to specific anatomical landmarks that would ensure equal placement for different measurement sessions. Furthermore, the vaginal electrode can shift or vibrate during dynamic tasks such as walking because of the impulse that needs to be absorbed by the body. In fact, several women reported the feeling that the vaginal electrode may have shifted. Owing the lack of instruments to control for this, it could not be checked. Consequently, it is possible that there is a measurement error inherent to the data.
For a possible longitudinal study, we were looking for a surrogate marker for the pelvic floor activity that can be quantified reliably in a movement laboratory. Therefore, the activity of M. Obliquus Externus, M. Rectus Abdominis, M. Erector Spinae, M. Multifidii Lumbalis, and M. Gluteus Maximus was measured using surface EMG. Three-dimensional kinematics of the body was recorded, and the joint angles in the sagittal plane of the ankle, knee, and hip as well as the global orientation in the sagittal plane of the pelvis were calculated.

Using the Pearson correlation coefficient, we were unable to find any strong correlation between maximal pelvic floor activity and any of the potential surrogate markers. Consequently, different surrogate markers need to be found before embarking on a longitudinal study assessing the training effect of unstable shoes on the pelvic floor muscles.

In this study, only women between 8 weeks and 6 months postpartum with no or a mild urinary incontinence were included. The results of this study cannot be translated to different populations, such as women with more than mild urinary incontinence or older women, in whom the pelvic floor activity and urinary incontinence are of high relevance (Fritel et al., 2012; Menezes et al., 2010; Milsom et al., 2009).

The recruitment of women for this study was difficult. One reason for this could be the fact that women between 8 weeks and 6 months postpartum are too busy caring for their infant. They often suffer from fatigue (Corwin \& Arbour, 2007). As a result, the time needed to travel to and from our laboratory and the time spent there (duration of data collection: approximately 3 hours) might have prevented many from participating in this study. Another reason for the difficulty in recruiting women could be that for this sample, symptoms had to be mild, so women may have been less motivated to support research about this topic. These assumptions may be supported by the study results showing that postpartum women's willingness 
to participate in pelvic floor muscle training is limited because of a variety of factors (Moossdorff-Steinhauser et al., 2015). Finally, many women may have been hesitant about using a vaginal electrode.

\section{CONCLUSIONS}

With regard to the pelvic floor musculature, it is not possible to make a recommendation concerning unstable shoes. We did not measure any short-term effect on the pelvic floor musculature caused by walking and standing in kyBoot shoes compared with walking and standing while barefoot. Whether or not the regular wearing of kyBoot shoes has a long-term effect on the pelvic floor needs to be addressed in future research.

\section{ACKNOWLEDGMENT}

The authors would like to acknowledge the contribution of Prof. Dr. Barbara Köhler to the study. Furthermore, the authors thank kybun AG for providing the footwear and Innosuisse for financially supporting the study.

\section{ETHICAL APPROVAL}

The study was approved by local ethical committee (Kantonale Ethikkommission Zürich, study ID 20150126).

\section{CONFLICT OF INTEREST}

The study received funding from Innosuisse (former Commission for Technology and Innovation).

kybun AG was involved in this study as industrial partner and financially contributed by providing the footwear. kybun AG was not involved in the design of the study protocol, data collection, analysis, and interpretation.

\section{References}

Abdullah, B., Ayub, S. H., Mohd Zahid, A. Z., Noorneza, A. R., Isa, M. R., \& Ng, P. Y. (2016). Urinary incontinence in primigravida: the neglected pregnancy predicament. European Journal of Obstetrics \& Gynecology and Reproductive Biology, 198, 110-115. https:// doi.org/10.1016/j.ejogrb.2016.01.006

Allahdin, S., \& Kambhampati, L. (2012). Stress urinary incontinence in continent primigravidas. Journal of Obstetrics and Gynaecology, 32(1), 2-5. https://doi.org/10.3109/01443615.2011.626542

Arrue, M., Ibañez, L., Paredes, J., Murgiondo, A., Belar, M., Sarasqueta, C., \& Diez-Itza, I. (2010). Stress urinary incontinence six months after first vaginal delivery. European Journal of Obstetrics \& Gynecology and Reproductive Biology, 150(2), 210-214. https:// doi.org/10.1016/j.ejogrb.2010.02.039

Barbosa, L., Boaviagem, A., Moretti, E., \& Lemos, A. (2018). Multiparity, age and overweight/obesity as risk factors for urinary incontinence in pregnancy: a systematic review and meta-analysis. International Urogynecology Journal. https://doi.org/10.1007/ s00192-018-3656-9

Bartling, S. J., \& Zito, P. M. (2016). Overview of pelvic floor dysfunction associated with pregnancy. International Journal of Childbirth Education, 31(1), 18-20.

$\mathrm{B} \varnothing, \mathrm{K}$. (2012). Pelvic floor muscle training in treatment of female stress urinary incontinence, pelvic organ prolapse and sexual dysfunction. World Journal of Urology, 30(4), 437-443. https://doi.org/10.1007/ s00345-011-0779-8

Bø, K., Haakstad, L. A. H., \& Voldner, N. (2007). Do pregnant women exercise their pelvic floor muscles? International Urogynecology Journal, 18(7), 733-736. https://doi.org/10.1007/s00192-006-0235-2
Bozkurt, M., Yumru, A. E., \& Şahin, L. (2014). Pelvic floor dysfunction, and effects of pregnancy and mode of delivery on pelvic floor. Taiwanese Journal of Obstetrics and Gynecology, 53(4), 452-458. https://doi.org/10.1016/j.tjog.2014.08.001

Corwin, E. J., \& Arbour, M. (2007). Postpartum fatigue and evidencebased interventions. The American Journal of Maternal/ Child Nursing, 32(4), 215-220. https://doi.org/10.1097/01. NMC.0000281959.71454.e5

Daly, D., Clarke, M., \& Begley, C. (2018). Urinary incontinence in nulliparous women before and during pregnancy: prevalence, incidence, type, and risk factors. International Urogynecology Journal, 29(3), 353-362. https://doi.org/10.1007/s00192-018-3554-1

Danforth, K. N., Townsend, M. K., Lifford, K., Curhan, G. C., Resnick, N. M., \& Grodstein, F. (2006). Risk factors for urinary incontinence among middle-aged women. American Journal of Obstetrics and Gynecology, 194(2), 339-345. https://doi.org/10.1016/j. ajog.2005.07.051

Davis, R. B., Õunpuu, S., Tyburski, D., \& Gage, J. R. (1991). A gait analysis data collection and reduction technique. Human Movement Science, 10(5), 575-587. https://doi.org/10.1016/01679457(91)90046-Z

Dolan, L. M., Walsh, D., Hamilton, S., Marshall, K., Thompson, K., \& Ashe, R. G. (2004). A study of quality of life in primigravidae with urinary incontinence. International Urogynecology Journal and Pelvic Floor Dysfunction, 15(3), 160-164. https://doi.org/10.1007/ s00192-004-1128-x

Dumoulin, C., Cacciari, L. P., \& Hay-Smith, E. J. C. (2018). Pelvic floor muscle training versus no treatment, or inactive control 
treatments, for urinary incontinence in women. Cochrane Database of Systematic Reviews. https://doi.org/10.1002/14651858. CD005654.pub4

Dumoulin, C., Glazener, C., \& Jenkinson, D. (2011). Determining the optimal pelvic floor muscle training regimen for women with stress urinary incontinence. Neurourology and Urodynamics, 30(5), 746753. https://doi.org/10.1002/nau.21104

Dumoulin, C., Hay-Smith, E. J. C., \& Mac Habée-Séguin, G. (2014). Pelvic floor muscle training versus no treatment, or inactive control treatments, for urinary incontinence in women. Cochrane Database of Systematic Reviews, (5). https://doi.org/10.1002/14651858. CD005654.pub3

Elenskaia, K., Haidvogel, K., Heidinger, C., Doerfler, D., Umek, W., \& Hanzal, E. (2011). The greatest taboo: urinary incontinence as a source of shame and embarrassment. Wiener Klinische Wochenschrift, 123(19-20), 607-610. https://doi.org/10.1007/ s00508-011-0013-0

Fritel, X., Ringa, V., Quiboeuf, E., \& Fauconnier, A. (2012). Female urinary incontinence, from pregnancy to menopause: a review of epidemiological and pathophysiological findings. Acta Obstetricia et Gynecologica Scandinavica, 91(8), 901-910. https://doi. org/10.1111/j.1600-0412.2012.01419.x

Fuselier, A., Hanberry, J., Lovin, M. J., \& Gomelsky, A. (2018). Obesity and stress urinary incontinence: impact on pathophysiology and treatment. Current Urology Reports, 19(1). https://doi.org/10.1007/ s11934-018-0762-7

Gyhagen, M., Bullarbo, M., Nielsen, T. F., \& Milsom, I. (2013). The prevalence of urinary incontinence 20 years after childbirth: a national cohort study in singleton primiparae after vaginal or caesarean delivery. BJOG: An International Journal of Obstetrics \& Gynaecology, 120(2), 144-151. https://doi.org/10.1111/j.14710528.2012.03301.x

Hansen, B. B., Svare, J., Viktrup, L., Jørgensen, T., \& Lose, G. (2012). Urinary incontinence during pregnancy and 1 year after delivery in primiparous women compared with a control group of nulliparous women. Neurourology and Urodynamics, 31(4), 475-480. https:// doi.org/10.1002/nau.21221

Haylen, B. T., de Ridder, D., Freeman, R. M., Swift, S. E., Berghmans, B., Lee, J., ... Schaer, G. N. (2010). An International Urogynecological Association (IUGA)/International Continence Society (ICS) joint report on the terminology for female pelvic floor dysfunction. International Urogynecology Journal, 21(1), 5-26. https://doi.org/10.1007/s00192-009-0976-9

Hermansen, I. L., O’Connell, B. O., \& Gaskin, C. J. (2010). Women's Explanations for Urinary Incontinence, Their Management Strategies, and Their Quality of Life During the Postpartum Period. Journal of Wound, Ostomy and Continence Nursing, 37(2), 187192.

Hermens, H. J., Freriks, B., Merletti, R., Stegeman, D., Blok, J., Rau, G., Hägg, G. (1999). European Recommendations for Surface ElectroMyoGraphy (Seniam 8). Enschede (NL): Roessing Research and Development.

Hilde, G., Stær-Jensen, J., Ellström Engh, M., Brækken, I. H., \& Bø, K. (2012). Continence and pelvic floor status in nulliparous women at midterm pregnancy. International Urogynecology Journal, 23(9), 1257-1263. https://doi.org/10.1007/s00192-012-1716-0

Junginger, B., Baessler, K., Sapsford, R., \& Hodges, P. W. (2010). Effect of abdominal and pelvic floor tasks on muscle activity, abdominal pressure and bladder neck. International Urogynecology Journal, 21(1), 69-77. https://doi.org/10.1007/s00192-009-0981-z

Khamis, S., \& Yizhar, Z. (2007). Effect of feet hyperpronation on pelvic alignment in a standing position. Gait \& Posture, 25(1), 127-134. https://doi.org/10.1016/j.gaitpost.2006.02.005

Kocaöz, S., Talas, M. S., \& Atabekoğlu, C. S. (2010). Urinary incontinence in pregnant women and their quality of life. Journal of Clinical Nursing, 19(23-24), 3314-3323. https://doi.org/10.1111/ j.1365-2702.2010.03421.x

Landry, S. C., Nigg, B. M., \& Tecante, K. E. (2010). Standing in an unstable shoe increases postural sway and muscle activity of selected smaller extrinsic foot muscles. Gait \& Posture, 32(2), 215-219.

Lee, K. (2018). Activation of Pelvic Floor Muscle During Ankle Posture Change on the Basis of a Three-Dimensional Motion Analysis System. Medical Science Monitor: International Medical Journal of Experimental and Clinical Research, 24, 7223-7230. https://doi. org/10.12659/MSM.912689

Luginbuehl, H., Greter, C., Gruenenfelder, D., Baeyens, J.-P., Kuhn, A., \& Radlinger, L. (2013). Intra-session test-retest reliability of pelvic floor muscle electromyography during running. International Urogynecology Journal, 24(9), 1515-1522. https://doi.org/10.1007/ s00192-012-2034-2

MacArthur, C., Glazener, C. M., Wilson, P. D., Lancashire, R. J., Herbison, G. P., \& Grant, A. M. (2006). Persistent urinary incontinence and delivery mode history: a six-year longitudinal study. BJOG: An International Journal of Obstetrics and Gynaecology, 113(2), 218-224. https://doi.org/10.1111/j.14710528.2005.00818.x

Marecki, M., \& Seo, J. Y. (2010). Perinatal urinary and fecal incontinence, suffering in silence. Journal of Perinatal \& Neonatal Nursing, 24(4), 330-340.

Martínez Franco, E., Parés, D., Lorente Colomé, N., Méndez Paredes, J. R., \& Amat Tardiu, L. (2014). Urinary incontinence during pregnancy. Is there a difference between first and third trimester? European Journal of Obstetrics \& Gynecology and Reproductive Biology, 182, 86-90. https://doi.org/10.1016/j.ejogrb.2014.08.035

Menezes, M., Pereira, M., \& Hextall, A. (2010). Predictors of female urinary incontinence at midlife and beyond. Maturitas, 65(2), 167171. https://doi.org/10.1016/j.maturitas.2009.10.004

Milsom, I., Altman, D., Lapitan, M. C., Nelson, R., Sillén, U., \& Thom, D. (2009). Epidemiology of Urinary (UI) and Faecal (FI) Incontinence and Pelvic Organ Prolapse (POP). In P. Abrams, L. Cardozo, S. Khoury, \& A. Wein (Eds.), Incontinence (4th ed., pp. 35-111). Paris: 4th International Consultation on Incontinence.

Moossdorff-Steinhauser, H. F. A., Albers-Heitner, P., Weemhoff, M., Spaanderman, M. E. A., Nieman, F. H. M., \& Berghmans, B. (2015). Factors influencing postpartum women's willingness to participate in a preventive pelvic floor muscle training program: a web-based survey. European Journal of Obstetrics \& Gynecology 
and Reproductive Biology, 195, 182-187. https://doi.org/10.1016/j. ejogrb.2015.10.009

Mørkved, S., \& B $\varnothing$, K. (2014). Effect of pelvic floor muscle training during pregnancy and after childbirth on prevention and treatment of urinary incontinence: a systematic review. British Journal of Sports Medicine, 48(4), 299-310. https://doi.org/10.1136/ bjsports-2012-091758

Mørkved, S., Salvesen, K. Å., B $\varnothing$, K., \& Eik-Nes, S. (2004). Pelvic floor muscle strength and thickness in continent and incontinent nulliparous pregnant women. International Urogynecology Journal, 15(6), 384-390. https://doi.org/10.1007/s00192-004-1194-0

Neumann, P., \& Gill, V. (2002). Pelvic floor and abdominal muscle interaction: EMG activity and intra-abdominal pressure. International Urogynecology Journal and Pelvic Floor Dysfunction, 13(2), 125-132. https://doi.org/10.1007/s001920200027

Nigg, B., Hintzen, S., \& Ferber, R. (2006). Effect of an unstable shoe construction on lower extremity gait characteristics. Clinical Biomechanics, 21(1), 82-88. https://doi.org/10.1016/j. clinbiomech.2005.08.013

Nygaard, I. (2006). Urinary incontinence: Is cesarean delivery protective? Seminars in Perinatology, 30(5), 267-271. https://doi. org/10.1053/j.semperi.2006.07.007

Nygaard, I. E., Glowacki, C., \& Saltzman, C. L. (1996). Relationship between foot flexibility and urinary incontinence in nulliparous varsity athletes. Obstetrics and Gynecology, 87(6), 1049-1051.

Pregazzi, R., Sartore, A., Troiano, L., Grimaldi, E., Bortoli, P., Siracusano, S., \& Guaschino, S. (2002). Postpartum urinary symptoms: prevalence and risk factors. European Journal of Obstetrics \& Gynecology and Reproductive Biology, 103(2), 179182. https://doi.org/10.1016/S0301-2115(02)00045-3

Press, J. Z., Klein, M. C., Kaczorowski, J., Liston, R. M., \& von Dadelszen, P. (2007). Does cesarean section reduce postpartum urinary incontinence? A systematic review. Birth, 34(3), 228-237. https://doi.org/10.1111/j.1523-536X.2007.00175.x

Price, N., Dawood, R., \& Jackson, S. R. (2010). Pelvic floor exercise for urinary incontinence: A systematic literature review. Maturitas, 67(4), 309-315. https://doi.org/10.1016/j.maturitas.2010.08.004

Sangsawang, B. (2014). Risk factors for the development of stress urinary incontinence during pregnancy in primigravidae: a review of the literature. European Journal of Obstetrics \& Gynecology and Reproductive Biology, 178, 27-34. https://doi.org/10.1016/j. ejogrb.2014.04.010

Sangsawang, B., \& Sangsawang, N. (2013). Stress urinary incontinence in pregnant women: a review of prevalence, pathophysiology, and treatment. International Urogynecology Journal, 24(6), 901-912. https://doi.org/10.1007/s00192-013-2061-7

Sapsford, R. R., \& Hodges, P. W. (2001). Contraction of the pelvic floor muscles during abdominal maneuvers. Archives of Physical Medicine and Rehabilitation, 82(8), 1081-1088. https://doi. org/10.1053/apmr.2001.24297

Sapsford, R. R., Hodges, P. W., Richardson, C. A., Cooper, D. H., Markwell, S. J., \& Jull, G. A. (2001). Co-activation of the abdominal and pelvic floor muscles during voluntary exercises. Neurourology and Urodynamics, 20(1), 31-42.
Stöggl, T., Haudum, A., Birklbauer, J., Murrer, M., \& Müller, E. (2010). Short and long term adaptation of variability during walking using unstable (Mbt) shoes. Clinical Biomechanics, 25(8), 816-822. https://doi.org/10.1016/j.clinbiomech.2010.05.012

Tähtinen, R. M., Cartwright, R., Tsui, J. F., Aaltonen, R. L., Aoki, Y., Cárdenas, J. L., Tikkinen, K. A. O. (2016). Long-term Impact of Mode of Delivery on Stress Urinary Incontinence and Urgency Urinary Incontinence: A Systematic Review and Meta-analysis. European Urology, 70(1), 148-158. https://doi.org/10.1016/j. eururo.2016.01.037

Tateuchi, H., Wada, O., \& Ichihashi, N. (2011). Effects of calcaneal eversion on three-dimensional kinematics of the hip, pelvis and thorax in unilateral weight bearing. Human Movement Science, 30(3), 566-573. https://doi.org/10.1016/j.humov.2010.11.011

Thom, D. H., \& Rortveit, G. (2010). Prevalence of postpartum urinary incontinence: a systematic review. Acta Obstetricia et Gynecologica Scandinavica, 89(12), 1511-1522. https://doi.org/1 $0.3109 / 00016349.2010 .526188$

Van Geelen, H., Ostergard, D., \& Sand, P. (2018). A review of the impact of pregnancy and childbirth on pelvic floor function as assessed by objective measurement techniques. International Urogynecology Journal, 29(3), 327-338. https://doi.org/10.1007/ s00192-017-3540-z

Wesnes, S. L., Hannestad, Y., \& Rortveit, G. (2017). Delivery parameters, neonatal parameters and incidence of urinary incontinence six months postpartum: a cohort study. Acta Obstetricia et Gynecologica Scandinavica, 96(10), 1214-1222. https://doi.org/10.1111/aogs.13183

Wesnes, S. L., Hunskaar, S., \& Rortveit, G. (2012). Epidemiology of urinary incontinence in pregnancy and postpartum. In A. Alhasso (Ed.), Urinary Incontinence (pp. 21-40). https://doi. org/10.5772/33742

Wesnes, S. L., \& Lose, G. (2013). Preventing urinary incontinence during pregnancy and postpartum: a review. International Urogynecology Journal, 24(6), 889-899. https://doi.org/10.1007/ s00192-012-2017-3

Woodley, S. J., Boyle, R., Cody, J. D., Mørkved, S., \& Hay-Smith, E. J. C. (2017). Pelvic floor muscle training for prevention and treatment of urinary and faecal incontinence in antenatal and postnatal women. Cochrane Database of Systematic Reviews, 12. https://doi. org/10.1002/14651858.CD007471.pub3

Zhou, H.-H., Shu, B., Liu, T.-Z., Wang, X.-H., Yang, Z.-H., \& Guo, Y.-L. (2018). Association between parity and the risk for urinary incontinence in women: A meta-analysis of case-control and cohort studies. Medicine, 97(28), e11443. https://doi.org/10.1097/ MD.0000000000011443

Živković, K., Živković, N., Župić, T., Hodžić, D., Mandić, V., \& Orešković, S. (2016). Effect of delivery and episiotomy on the emergence of urinary incontinence in women: Review of literature. Acta Clinica Croatica, 55(4), 615-623. https://doi.org/10.20471/ acc.2016.55.04.12 